\section{EXTENSIVE LOSS OF OS FRONTIS AND BRAIN.}

\section{To the Editor of The LANCET.}

Sir:-On the 17 th nlt. I was called to a girl, about 11 years of age, whose head had been struck by the handle of the winch (in rapid motion at the cime) attached to a diawwell. The sufferer was insensible and motionless, and remained in this state until, with the kind assistance of another surgeon (Mr. Gorst), I had remored some pieces of bone that $I$ ascertained were pressing on parts of the brain, which remained comparatively uninjured by the accident. On ascertaining the extent of the mischief (the greater portion of the frontal bone and brain immediately in contact with it had been dashed from the head) we deemed it utterly impossible to save the life of our patient, and, therefore, our treatment consisted in relieving her sufferings through the few remaining hours of her existence, \&c. After lingering 104 hours, during which time she was, for the most part, perfectly sensible, and retaining to the last all the natural functions of the body, she died.

This case, physiologically, as well as phrenologically, involves some points of considerable interest. A great portion of the cerebrum was not only destroyed, but completely swept away, yet the patient survived for upwards of four days, and as many nights, retaining her mental faculties entire to the last hour of her existence; nor was her sight impaired, the pupils of both eyes acting in the most regular and natural manner. How these things could exist under such circumstances, and accord with the doctrines of phrenology, as they are at present taught, I am unable to determine. Perhaps some of your more able correspondents will have the kindness to inform me. I am, Sir, your most obedient servant,

Joseph Harding Drawbridge, M.K.C.S., and Lic. Apoth. Hall, London. New Ferry, Cheshire, October 21, 1838.

\section{CURE OF CLUB-FOOT.}

\section{To the Editor of TIIE Lancet.}

Sir:-Will you allow me, through your extensively-circulated Journal, to add my testimony in favour of the operation of dividing the tendons in cases of contraction of the parts to which they are connected, and particularly in the varieties of club-foot. From infancy $I$ experienced a degree of in. convenience from a degree of rigidity of the right ankle-joint, arising from shortness of the gastrocnemii and tendo Achillis. I could not bend the joint beyond the right angle; the foot was higher in the arch of the tarsus than the other, and shorter by about tro lines. During boyhood the limitation of the motion of the joint did not affect the bulk of the limb; but about twelve years of age I perceived that it wanted a little of its proper bulk, and at the time when I applied to $\mathrm{Dr}$. Little, besides the reduced bulk of the muscles, there was a perceptible deficiency in the dimensions of the tibia. The inconvenience which I experienced, though not very sreat, was one of constant recurrence, ard was felt in mounting a stair, in walking np hill, on horseback, from the unfirm position of the foot in the stirrup-iron, in danc. ing, and, in short, in every case where free flexion of the joint was required. I con. sulted Dr. Little of 126, Fenchurch-street, London, and his opinion being for the division of the tendo Achillis I went up to London as soon as indispensable engage ments would permit, and on the 12th of March last submitted to the operation. $\mathrm{Dr}$. Little, assisted by Mr. Hamilton of the London Hospital, performed the operation with his usual skill and dexterity; it ocenpied only four or five seconds, was scarcely more painful than the common operation of bloodletting; there did not escape one single drop of blood, and I experienced, after. wards, no uncomfortable feeling. I lay on a sofa for three days; had the foot-bord applied on the third, the wound in the skin Laving firmly united; the fiexion of the joint gradually progressed till, on the 22nd day from the operation, it was at as great a degree on the operated side as conld be given to the other; the foot-board was nor left off ; I walked about the room with only a commor slipper on the foot. On the git of April I walked out for the distance of one mile; on the 13th I walked a distance of five miles, and in the beginning of Dlay returned home entirely freed from the stiff. ness and inconvenience in the joint which I had previously felt; the slight lameness set maining, from the altered condition of the part, soon entirely disappeared, and I nor enjoy all the benefit which I was led to expect. I have not only to acknowledgre the cxtreme kindness and attention of Dr. Little to me as a patient, but bis polite and gentlemanly attention as a member of the profession. I can and nothing that call raise the esteem which Dr. Little has already acquired; the testimony of those who have before me experienced his kindness is more than sufficient, only allors to to add, that after having thus experiencel the treatment followed by Dr. Little, and seen some other cases of his while in Lotrdon, I have done the operation here with the most entire success. I am, $\mathrm{Sir}$, yoit very obedient servant,

Frederick Cummino, M.D.

Dundee, October 17, 1838. 